\title{
Caracterización psicosocial y de motivos de consulta de la población asistente a 28 Centros de Atención Psicológica Universitarios en Colombia *
}

\section{Psychosocial Characterization and Reasons for Consultation of the Population Attending 28 University Centers for Psychological Care in Colombia}

\author{
Tatiana Colón Llamas \\ Pontificia Universidad Javeriana, Colombia \\ ORCID: http://orcid.org/0000-0002-9143-6007 \\ Andrea Escobar Altare \\ Pontificia Universidad Javeriana, Colombia \\ ORCID: http://orcid.org/0000-0002-7373-297X \\ Andrés Santacoloma Giraldo \\ Pontificia Universidad Javeriana, Colombia \\ ORCID: http://orcid.org/0000-0003-4607-8025 \\ Alejandro Granados-García \\ Pontificia Universidad Javeriana, Colombia \\ ORCID: http://orcid.org/0000-0001-7201-4872 \\ SOCORRo Moreno LunA \\ Pontificia Universidad Javeriana, Colombia \\ ORCID: http://orcid.org/0000-0002-4119-4409 \\ Luis Manuel Silva Martin \\ Pontificia Universidad Javeriana,, Colombia \\ ORCID: http://orcid.org/0000-0001-7051-0186
}

a Autor de correspondencia. Correo electrónico: vcolon@javeriana.edu.co

Para citar este artículo: Colón Llamas, T., Escobar Altare, A., Santacoloma Giraldo, A., GranadosGarcía, A., Moreno Luna, S., \& Silva Martin, L. M. (2019). Caracterización psicosocial y de motivos de consulta de la población asistente a 28 Centros de Atención psicológica universitarios en Colombia. Universitas Psychologica, 18(4), 1-23. https:// doi.org /10.11144/Javeriana.upsy18-4.cpmc

\section{RESUMEN}

En Colombia, los Centros de Atención Psicológica Universitarios ofrecen servicio de psicoterapia. El incremento de la demanda de atención psicológica en estos Centros y la diversidad de las personas que asisten a los mismos hacen necesario conocer las características de la población consultante y sus pedidos de ayuda, con el fin de producir información relevante que oriente el diseño futuro de estrategias de evaluación e intervención a nivel de la atención clínica y psicosocial. El objetivo de este estudio fue establecer una caracterización psicosocial y de los motivos de consulta de las personas que asisten a los Centros de Atención Psicológica Universitarios. Se realizó una encuesta a 1525 personas que asistieron por primera vez a 28 de estos centros durante el período de marzo a julio de 2018, en siete regiones del país: Bogotá, Antioquia, Costa Caribe, Eje Cafetero, Tolima, Huila y Valle del Cauca. Los resultados mostraron que las dificultades emocionales y del estado de ánimo, los problemas de relación con el grupo primario de apoyo y las pérdidas y duelos son los principales motivos para consultar. La violencia intrafamiliar, la afectación directa e indirecta por el conflicto armado y las condiciones 
de inseguridad en el entorno cercano son factores de riesgo psicosocial en la población. Se recomienda la implementación de intervenciones psicológicas y psicosociales que privilegien las características específicas de los consultantes, así como la estructuración de equipos interdisciplinarios para la recuperación y el bienestar de la población.

Palabras clave

caracterización psicosocial; atención psicológica; motivos de consulta; salud mental.

\begin{abstract}
Colombian University Centers for Psychological Care offer psychotherapy service. The increase in the demand of this service and the diversity of the population attending those centers, show the necessity of having a more accurate approach to the characteristics of the consulting population and their psychological requests. The above with the aim of producing relevant information that can guide the design of strategies of evaluation and intervention in both clinical and psychosocial attention. Therefore, the objective of this study was to stablish a psychosocial characterization of the consulting population and their reasons for consultation. For this purpose, a survey of 1525 people was conducted, in which all of the consultants attended for the first time one of the 28 Centers located in seven regions of the country: Bogotá, Antioquia, Costa Caribe, Eje Cafetero, Tolima, Huila, and Valle del Cauca, between March and July 2018. The results showed three main reasons for consulting: emotional difficulties and mood state, problems in their relation to their primary support group and loss and grief. In addition, the study indicates that the three main psychosocial risk factors are domestic violence, directly and indirectly affectation by armed conflict and insecurity conditions in their close environment. As a general conclusion, it is recommended the implementation of psychological and psychosocial interventions in accordance with the specific characteristics of consultants on one hand, and on the other, the conformation of interdisciplinary teams working in the recovery and welfare of the population.
\end{abstract}

Keywords

psychosocial characterization; psychological attention; reasons for consultation; mental health.

Colombia ha tenido una prolongada historia de conflicto armado, cuyas distintas expresiones de violencia (social, política, económica, ambiental, etc.) han impactado directa e indirectamente la salud mental de la población, moviendo a las personas a buscar atención y apoyo psicológico para aliviar su sufrimiento. La Organización Mundial de la Salud (OMS, 2013) ha planteado, para el estudio del campo de la salud mental, tener en cuenta las características individuales, así como los llamados determinantes sociales, es decir, factores culturales, sociales, económicos, políticos y ambientales. La investigación orientada a quienes buscan atención psicológica debe indagar por dichos factores, teniendo en cuenta que, por décadas, el conflicto armado en Colombia ha propiciado el desplazamiento forzado de poblaciones -al que se atribuye el aumento de la pobreza, del desempleo y de la violencia urbana, etc.-, conllevando cambios en las características sociodemográficas y psicosociales de la población y aumentando su riesgo de presentar problemas o trastornos mentales.

La Encuesta Nacional de Salud Mental (Ministerio de Salud y Protección Social, 2015) presenta, en este sentido, un panorama preocupante respecto del porcentaje de personas que refirieron haber tenido alguna dificultad relacionada con la salud mental en un determinado momento de su vida, siendo esto así para el $2.8 \%$ de los niños, el $51.5 \%$ de los adolescentes, el $36.1 \%$ de los adultos entre 18 y 44 años y el $35.6 \%$ en mayores de 44 años. Asimismo, da cuenta de la amplia brecha entre el número de personas que refieren presentar algún tipo de problema de salud mental en los últimos 12 meses y la cantidad de solicitudes de atención, la cual fue menor al $50 \%$. De este modo, más del $50 \%$ de la población con algún problema de salud mental, no necesariamente psicopatológico, se ha quedado sin atención, generando un mayor riesgo de desarrollar un trastorno y de producir mayores impactos en la calidad de vida de las personas. Según la encuesta, la terapia más solicitada es la psicoterapia por psicología en el $58.3 \%$ de los casos de niños y el $72.7 \%$ de los casos de adultos.

Teniendo en cuenta que los servicios psicológicos están considerablemente limitados en el Plan Obligatorio de Salud -en términos de duración y constancia de los procesos-, la atención psicológica que prestan las instituciones universitarias se ha constituido en una alternativa cada vez más solicitada por los ciudadanos, debido a los bajos costos, la disponibilidad del servicio, su calidad y 
continuidad. El incremento de la demanda de atención psicológica en los centros universitarios y la diversidad de las personas que asisten a los mismos evidencian la importancia de conocer las características de la población consultante y sus pedidos de ayuda, con el fin de producir información relevante que oriente el diseño futuro de estrategias de evaluación e intervención a nivel de la atención clínica y psicosocial.

En el presente estudio, se entendió por motivo de consulta el malestar psicológico asociado a signos y síntomas, y la dimensión afectiva que moviliza a un sujeto a buscar alivio y una comprensión subjetiva de su sufrimiento. Para obtener una imagen detallada de esto, se indagó por la historia de su problemática, la duración e intensidad de la misma, las ideas sobre el origen de su problemática, el impacto que esta ha tenido en su vida, los intentos de solución y los tratamientos previos. El malestar psicológico expresado en el motivo de consulta ha sido asociado a factores psicosociales (Cáceres, Salazar, Varela, \& Tovar, 2006, de la Portilla Maya, Montoya Londoño, Dussán Lubert, \& López Jaramillo, 2016; Gómez, 2010), por lo que se hace necesario caracterizar tanto los riesgos como los recursos que tiene la población a este nivel.

La visión de la Política Nacional de Salud Mental (Ministerio de Salud y Protección Social, 2018), destacando un enfoque psicosocial, reconoce "la integralidad de las personas teniendo en cuenta el contexto en el que se han desenvuelto, los hechos que han vivido, el significado que les han dado a estos hechos, el sufrimiento que han experimentado y las capacidades con las que cuentan las personas y comunidades para recuperarse y materializar sus proyectos de vida" (p. 18). A partir de esto, es posible identificar factores de protección y de riesgo psicosocial en la vida de las personas. Por factores de protección se entienden aquellas condiciones en las relaciones interpersonales o en el contexto del sujeto que le previene de sufrir excesivamente posibles desajustes sociales y emocionales (Ministerio de Salud y Protección Social, 2017). Si bien la naturaleza de estos factores es heterogénea, varios autores han resaltado la importancia del grupo primario de apoyo, en la mayoría de los casos, la familia (Beckham \& Leber, 1997; Clark, Beck, \& Alford, 1999). Otros factores de protección relevantes son los vínculos de calidad, las redes de apoyo, el nivel educativo y el uso adecuado del tiempo libre (Bezanilla et al., 2017).

Por su parte, por factores de riesgo se entienden aquellos elementos que aumentan la vulnerabilidad de una persona a padecer malestar emocional y desajustes psicosociales (Ministerio de Salud y Protección Social, 2017). Se suelen asociar con precariedad en los recursos psicosociales y, en el caso particular del país, con la situación de violencia política, el conflicto armado y el crimen organizado, presentes en un sector considerable de la población (Arroyave, 2002). Los factores de riesgo, como tal, constituyen condiciones relativamente constantes en el medio en el que se desenvuelve el sujeto, especialmente el maltrato físico, sexual o psicológico, el abandono real o emocional, la negligencia familiar o estatal y los patrones recurrentes en educación y crianza (Cáceres et al., 2006).

Existen antecedentes nacionales e internacionales de la presente investigación que evidencian una diversidad importante en el abordaje del tema. En países como España, se han realizado estudios clínicos, pero pocos de ellos incluyen el elemento psicosocial, limitándose sobre todo al análisis de datos demográficos, el motivo de consulta y el diagnóstico final de los pacientes (Caballero, Bobes, Vilardaga, \& Rejas, 2009; Calsina-Berna, Moreno Millán, González-Barboteo, Solsona Díaz, \& Porta Sales, 2011; de Miguel-Álvaro, 2018; Labrador, 2010). En países latinoamericanos, la producción es diferente: en la literatura científica producida en México (Espinosa Muñoz, Orozco Ramírez, \& Ybarra Sagarduy, 2015; González-Villalobos \& Marrero, 2017; Juárez, 2004; Sosa, Romero, Blum, Zarco, \& Medina-Mora, 2018), Argentina (Quesada, 2004) y Costa Rica (Maroto-Vargas, Molina-Fallas, \& Prado-Calderón, 2017), se han realizado comparaciones más detalladas de los factores sociodemográficos, psicosociales, 
criterios clínicos y cierta sistematización de los motivos de consulta. También se encuentran reflexiones sobre las formas de presentación que adquieren los síntomas y las demandas psicológicas en la actualidad (Campodónico, 2018), así como comparaciones de las demandas terapéuticas en contextos públicos y privados (Ponce, 2016). En el ámbito nacional, se encuentran estudios epidemiológicos adelantados por estamentos públicos, como la Encuesta Nacional de Salud Mental de 2015 o por distintos centros de salud independientes, incluyendo aquellos vinculados a instituciones educativas.

Londoño et al. (2010) buscaron identificar relaciones entre factores psicosociales $y$ trastornos mentales en 490 participantes de diferentes centros de atención psicológica de todo el país, a partir de la aplicación del cuestionario eje IV del DSM-IV (factores psicosociales y ambientales) y el Mini International Neuropsychiatric Interview (MINI).

Por su parte, Obando-Posada, RomeroPorras, Trujillo-Cano y Prada-Mateus (2017) intentaron relacionar los síntomas y diagnósticos clínicos de los consultantes con categorías tales como: motivos de consulta, procedimientos de evaluación e intervención, datos demográficos y factores psicosociales. La Universidad de Manizales ha realizado la caracterización de la población atendida y diversos estudios respecto de los factores psicosociales, motivos de consulta e impresiones diagnósticas, en el curso de los últimos 12 años. Se destacan los trabajos de López-Jaramillo, Montoya Londoño y Dussán Lubert (2012), de la Portilla Maya et al. (2016) y Narváez y Aguirre (2016). Los autores de dichas investigaciones realizaron llamados de atención a los futuros estudios a realizarse, en tanto se carece de un "retrato fiel" \# no centralizado\# de la población general que es atendida por los diversos Centros de Atención Psicológica del país. Cabe destacar la investigación de Gómez y Pérez (2017) cuyo objetivo fue identificar las particularidades de los motivos de consulta psicológica de los estudiantes universitarios que acudieron durante los años 2012, 2013 y 2014 a la Dirección de Bienestar Universitario de la Universidad de Antioquia.

Se evidencia, a partir de la literatura consultada, que son pocos los estudios que buscan caracterizar y relacionar factores psicosociales y motivos de consulta dentro de la atención psicológica. Y son aún más escasos los estudios que abarcan a distintas instituciones de atención psicológica a nivel nacional, regional y local. La limitada producción científica en esta área destaca la amplitud del problema por investigar. Ya sea desde ámbitos de prevención o atención, desde contextos hospitalarios o centros universitarios, considerando criterios clínicos, psicosociales o de ambos, la necesidad de caracterizar a una población tan heterogénea como la que solicita atención por psicología, es una permanente y renovada invitación a la clínica psicológica a continuar contribuyendo en esta línea de trabajo. Es así como el presente estudio tuvo como objetivo establecer una caracterización psicosocial y de los motivos de consulta de las personas que asistieron por primera vez a 28 Centros de Atención Psicológica Universitarios en Colombia.

\section{Método}

\section{Diseño}

Se desarrolló un estudio mixto (cualitativo/ cuantitativo) descriptivo, de caracterización, transversal, tipo censo, que mediante una encuesta heteroaplicada se aproximó a la identificación de la población que asiste a 28 Centros de Atención Psicológica Universitarios de 16 ciudades del país.

\section{Población}

El estudio contó con la participación de 1525 personas que consultaron por primera vez en los centros, durante el período de marzo a julio de 2018. La muestra total se distribuyó así: 869 adultos $(56.9 \%)$ entre 18 y 80 años de edad (M $=30.8 ; \mathrm{DE}=13.03) .238$ adolescentes $(15.6 \%)$ 
entre 13 y 17 años $(M=15.2 ; D E=1.54)$ y 418 niños $(27.4 \%)$ entre 3 y 12 años $(M=8.4 ; D E=$ 2.17). La distribución por sexo fue de 869 mujeres (56.9\%) y 656 hombres (43\%) (Tabla 1 ).

\section{Tabla 1}

Distribución de la población por grupos de edad en años

\begin{tabular}{ccccccc}
\hline Grupo de edad & \multicolumn{2}{c}{ Hombre } & \multicolumn{2}{c}{ Mujer } & \multicolumn{2}{c}{ Total } \\
\cline { 2 - 7 } (en años) & Frecuencia & $\%$ & Frecuencia & $\%$ & Frecuencia & $\%$ \\
\hline 3 a 11 & 276 & 18 & 142 & 9.3 & 418 & 27.4 \\
12 a 17 & 110 & 7.2 & 128 & 8.3 & 238 & 15.6 \\
18 a 30 & 143 & 9.3 & 359 & 23.5 & 502 & 32.9 \\
31 a 60 & 114 & 7.4 & 224 & 14.6 & 338 & 22.1 \\
61 a 80 & 13 & 0.8 & 16 & 1 & 29 & 1.9 \\
\hline Total $(N=1525)$ & 656 & 42.7 & 869 & 56.7 & 1525 & 100 \\
\hline
\end{tabular}

La distribución de la muestra por regiones del país fue la siguiente: 642 (42\%) personas en ocho centros de Bogotá y Cundinamarca; 355 (23.2\%) en 6 centros de Antioquia; 192 (12.5 $\%)$ en 3 centros de Tolima-Huila; 126 (8.2\%) en 3 centros del Eje Cafetero; 123 (8\%) en 4 centros de la Costa Caribe; 62 (4\%) en 2 centros del Valle del Cauca y 25 (1.6\%) en 2 centros de Santander. De acuerdo con la distribución por áreas urbana y rural, 888 personas (58.3\%) reportaron vivir en capital departamental; 536 (35.2 \%) en cabecera municipal y 97 (6.3 \%) en zonas rurales y/o veredales. En relación con las características étnicas de la muestra, 67 personas se reconocieron como afrodescendientes, 47 como indígenas, 4 como raizales del archipiélago de San Andrés, 1 como palenquero de San Basilio y 1 como Gitano/Rom.

Del total de la población de adultos y adolescentes, 779 personas (70.8 \%) reportaron tener alguna creencia o culto religioso, mientras que 321 (29.1\%) reportaron no tener filiación religiosa alguna. El catolicismo, con 603 personas (72.7\%), y el cristianismo, con 129 personas $(15.5 \%)$ son las creencias y/o cultos religiosos de mayor prevalencia.

En lo relativo a la distribución socioeconómica, 1423 personas se encuentran estratificadas así: 558 (39.2\%) en estrato 3; 499 (35.1\%) en estrato $2 ; 162$ (11.4\%) en estrato 1 ; 152 (10.7) en estrato 4 y 52 (3.6\%) en estratos 5 y 6 . Acerca del nivel de ingresos y su origen, 369 personas (26\%) reportaron recibir menos de un salario mínimo legal vigente (SMLV); 486 (32\%) reciben entre 1 y 2 SMLV y 246 (16 $\%)$ reportaron no recibir ingresos. La mayoría de los ingresos de la población proviene de salario, mesada y/o subsidio.

En cuanto a la tenencia de vivienda, 575 personas (38\%) residen en arriendo; 501 (33 $\%)$ en vivienda propia totalmente pagada y 199 (13\%) en vivienda propia que están pagando. El acceso y cobertura de servicios básicos en los hogares \#agua, acueducto, alcantarillado, recolección de basuras, electricidad y gas\# está por encima del $94 \%$. La cobertura de servicios complementarios como telefonía e internet está alrededor del $70 \%$.

Por otro lado, 1437 personas (94\%) reportaron estar afiliadas al Sistema General de Seguridad Social en Salud. De estas, 1023 personas (71 $\%)$ reportaron afiliación al régimen contributivo; 335 (23\%) al régimen subsidiado; 42 (3\%) a un régimen especial; y 37 (3\%) no especificaron su tipo de afiliación.

\section{Instrumento}

Se construyó una encuesta con los siguientes ejes temáticos: 1) datos sociodemográficos tales como: edad, género, orientación sexual, estado civil, etnia, creencias/actitudes religiosas, ocupación, nivel educativo, lugar de residencia, estrato socioeconómico, servicio de salud, régimen de salud, personas a cargo, personas con las que vive, condiciones económicas y características del entorno donde vive; 2) factores de protección psicosocial, tales como: redes de apoyo, vínculos y uso del tiempo libre; 3) factores de riesgo psicosocial, tales como: situación familiar, violencia, conflicto armado, migración, duelo, salud, discapacidad, consumo de sustancias e ideación y conducta suicida y 4) motivo de consulta: contiene preguntas que pretenden realizar una descripción lo más detallada posible del motivo de consulta, historia de la problemática, ideas que tiene el consultante sobre la problemática, impacto que ha tenido en su vida, expectativas, intentos de solución y tratamientos psicológicos o psiquiátricos previos.

La encuesta cuenta con preguntas de tipo opción múltiple, única respuesta, una pregunta abierta (motivo de consulta) y campos de 
texto para profundizar en la información. Para aquella específicamente relacionada con el motivo de consulta, se dispuso un campo donde se consignó el mismo de manera literal. Se generaron preguntas cerradas sobre la remisión, el inicio y curso de la problemática, los factores relacionados con su aparición y mantenimiento, la afectación en las diferentes esferas de funcionamiento, las expectativas sobre el proceso terapéutico y las alternativas de manejo y tratamiento buscadas anteriormente. Es de anotar que la encuesta permitía el apoyo de un acudiente en el caso de presencia de condiciones de discapacidad en un sujeto que podía responder a la encuesta, pero requería de mediaciones particulares como lengua de señas o el acompañamiento de un tercero.

Una vez finalizado el diseño, un grupo de cuatro expertos con experiencia en neuropsicología, psicología clínica, psicología social y medición y evaluación psicológica, estimaron la pertinencia, relevancia y redacción de cada ítem (Escobar-Pérez \& Cuervo-Martínez, 2008; Miller \& Lovler, 2015).

Aplicación de la encuesta y elaboración de base de datos

El terapeuta -estudiante o profesional en psicología- consultó a cada sujeto su disposición a participar en el estudio; en caso afirmativo, diligenció el consentimiento informado -discriminando aquel elaborado para la población mayor de edad o el correspondiente a menores de edad-. A continuación, se aplicó la encuesta. Para este proceso, se diseñó un material de apoyo que consistía en un libro de respuesta que fue entregado a cada consultante para facilitar la lectura de aquellas preguntas que contaban con cinco o más opciones de respuesta.

Cada encuesta fue diligenciada en medio físico por el terapeuta. Un miembro del equipo designado en cada centro de atención psicológico universitario, verificó el correcto diligenciamiento de las encuestas y gestionó el envío de las mismas al equipo de investigadores de la Pontifica Universidad Javeriana. La digitación de los datos se llevó a cabo en una base de Excel@ ${ }^{\circledR}$. La base de datos fue construida según los principios de "datos ordenados" o "tidy data" (Wickham, 2014), para facilitar el ingreso y tratamiento de la información en cualquier programa de análisis de datos.

\section{Análisis descriptivo}

El análisis descriptivo se llevó a cabo en SPSS $®$, caracterizando con detalle la muestra en términos de los ejes de la encuesta. A la vez, se realizó un análisis de proporciones y relaciones entre las diferentes variables, tanto psicosociales como de motivos de consulta, a las que responde la encuesta. El análisis de los motivos de consulta se planeó en dos formas: 1) una parte cuantitativa descriptiva de los sub-ejes temáticos y 2) una parte cualitativa basada en un análisis temático de los motivos de consulta registrados de manera literal. Este análisis se realizó por medio de un proceso de categorización, cuyas categorías son producto de un ejercicio de triangulación entre un consenso de expertos de la red ISUAP (Instituciones de Servicios Universitarios de Atención Psicológica), los resultados de un análisis de frecuencia de aparición de palabras en el software $\mathrm{Nvivo}^{\circledR}$ en el cual fueron procesados 275 motivos de consulta de la base de datos de Consultores en Psicología de la Pontificia Universidad Javeriana y la revisión de literatura especializada. Esto derivó en la elaboración y definición de 31 categorías para el análisis de motivos de consulta que fueron considerados para el presente estudio (Ver Apéndices A, B y C).

\section{Resultados}

\section{Resultados de la población adulta}

\section{Características generales}

Del total de la muestra de adultos, el $76.1 \%$ tomó la decisión de asistir al psicólogo de manera voluntaria y el $23.9 \%$ fue remitido por otro 
profesional o institución de salud, educación o de justicia. Como se mostró en la Tabla 1, la mayor proporción de adultos está en el rango de edad de 18 a 30 años con un $58 \%$, seguido del rango de 31 a 60 años con $39 \%$ y finalmente de 61 a 80 años el $3 \%$.

\section{Tabla 2}

Características Generales Población Adulta

\begin{tabular}{|c|c|c|}
\hline Variable & Frecuencia & $\%$ \\
\hline \multicolumn{3}{|l|}{ Estado civil } \\
\hline Solteros & 545 & 62.8 \\
\hline Casados más de 2 años & 120 & 13.8 \\
\hline Unión libre más de 2 años & 77 & 8.9 \\
\hline Divorciado & 74 & 8.5 \\
\hline Unión libre menos de 2 años & 32 & 3.7 \\
\hline Casados menos de 2 años & 9 & 1 \\
\hline Viudos & 8 & 0.9 \\
\hline \multicolumn{3}{|l|}{ Estudia actualmente } \\
\hline Sí & 470 & 54.1 \\
\hline No & 398 & 45.9 \\
\hline \multicolumn{3}{|l|}{ Grado cursado } \\
\hline Educación media & 370 & 42.8 \\
\hline Técnico con título & 131 & 15.1 \\
\hline Universitario con título & 111 & 12.8 \\
\hline Tecnológico con título & 55 & 6.4 \\
\hline Posgrado con título & 46 & 5.3 \\
\hline \multicolumn{3}{|l|}{ Actividad laboral } \\
\hline Sí & 410 & 47.7 \\
\hline \multicolumn{3}{|l|}{ Vinculación laboral } \\
\hline Sí & 257 & 63.5 \\
\hline No & 148 & 36.5 \\
\hline \multicolumn{3}{|l|}{ Tipo de vinculación } \\
\hline Contrato a término indefinido & 124 & 48.6 \\
\hline Contrato a término fijo & 59 & 23.1 \\
\hline Contrato civil por prestación de servicios & 32 & 12.5 \\
\hline
\end{tabular}

Aspectos psicosociales relacionados con la salud mental

Dentro del estudio se indagó por diferentes factores psicosociales debido a su importante incidencia en la salud mental del ser humano. Las condiciones históricas, sociales y contextuales favorecen o afectan negativamente el desarrollo y uso de recursos para enfrentar la vida cotidiana y las tensiones que se presentan en el individuo, las familias y los grupos sociales.

Factores de protección psicosocial y redes de apoyo

El presente estudio consideró la conformación del grupo primario de apoyo, la percepción de satisfacción con la familia, las redes de apoyo y el uso del tiempo libre como condiciones de protección psicosocial.

Al indagar por el número de personas con quienes conviven los adultos, 233 (27.8\%) viven con dos personas; 226 (27\%) viven con cuatro o más personas; 208 (24.9\%) con tres personas; 126 (15.1\%) viven con una persona y 43 (5.1\%) viven solos. Las personas con quienes conviven son, en su mayoría, miembros de su familia de origen y/o miembros de su familia configurada posteriormente.

A nivel de las relaciones familiares se tuvo en cuenta el reporte de las personas frente a factores como el apoyo que recibe frente a sus problemas y necesidades, la expresión de sentimientos, la disposición frente a nuevos proyectos y el tiempo que comparten juntos. En relación con lo anterior, 360 personas (41.4\%) reportaron satisfacción alta con su familia, 418 (48.1\%) satisfacción media y 90 (10.3 \%) baja satisfacción familiar.

En cuanto a las entidades a las que se acude en busca de apoyo y asesoría, los resultados muestran que la población adulta asiste principalmente a instituciones o congregaciones religiosas (18.2 $\%)$, seguidas de instituciones de justicia (13.8 $\%)$, y de instituciones de apoyo a la familia (11.4\%). Es pertinente anotar que un 64.5 $\%$ de la población adulta reportó no haber hecho uso de estos servicios. Se indagó también acerca de las personas a quienes se acude para obtener ayuda con los problemas. $\mathrm{Al}$ respecto, la tendencia indica que la población adulta busca a los miembros de su familia (75\%), seguido de sus amigos $(59.2 \%)$ y la pareja (41.8 \%).

Por último, en lo concerniente al uso del tiempo libre, la población adulta reportó en su mayoría (73 \%) realizar actividades de ocio (leer, jugar videojuegos, ver televisión y navegar en internet), seguidas por actividades deportivas (40.6\%), actividades culturales (39.5\%) (cine, música y museos), actividades sociales (35\%) (voluntariados, trabajo comunitario y eventos religiosos) y actividades artísticas en menor proporción (22.6\%). 


\section{Factores de riesgo psicosocial}

El presente estudio consideró la afectación directa e indirecta por el conflicto armado en el país, la exposición a diversas situaciones de riesgo en el entorno, así como situaciones del ambiente próximo como el maltrato familiar y las pérdidas significativas.

\section{Afectación por el conflicto armado colombiano}

Al indagar por la incidencia del conflicto armado, se encontró que $103(11.9 \%)$ adultos reportaron algún tipo de relación directa con este, ya sea que involucraba a la persona o a un familiar en primer grado. Este grupo de personas se reconoció de una o varias de las siguientes maneras: 87 de ellos como víctimas, 12 como miembros de las Fuerzas Armadas, 11 como integrantes de algún grupo de apoyo o acompañamiento a comunidades y dos como exmiembros de un grupo armado organizado al margen de la ley. Por su parte, las 87 personas que se reconocen como víctimas del conflicto armado reportaron haber sufrido una o varias de las siguientes situaciones: desplazamiento forzado, 42 personas; amenazas, 33 personas; homicidio de familiares u otros significativos, 19 personas; pérdida o destrucción de bienes materiales, 19 personas; secuestro, 14 personas; extorsiones, 13 personas; atentados, 11 personas; desaparición forzada, cuatro personas; masacre, cuatro personas; trato cruel, inhumano o degradante, cuatro personas; otro tipo de victimización como ser espectadores de situaciones de violencia o retención, cuatro personas; reclutamiento forzado, dos personas; violencia sexual, una persona.

El estudio también permitió identificar que 383 adultos (51.1 \%) reconocen uno o varios de los siguientes tipos de afectación indirecta, relacionados con el conflicto armado que ha vivido nuestro país: 159 personas manifestaron "sentir miedo de convertirse en víctima directa"; 125 personas "evitan noticias sobre política u orden público"; 125 personas mencionaron "sentir que nada de lo que puedan hacer contribuye al cambio del país"; 103 personas "han dejado de expresar públicamente las opiniones políticas"; 101 personas "han restringido su movilidad en el territorio nacional"; 69 personas reconocieron "sentir muy poco impacto emocional frente a las noticias relacionadas con el conflicto"; 69 personas "evitan pertenecer a grupos o participar en asuntos comunitarios" y 25 personas reportaron otros tipos de afectación indirecta tales como afectación emocional, laboral y/o económica, la presencia de antecedentes de relación directa con el conflicto armado, la sensación de inconformismo, sentimientos de desconfianza y desesperanza.

\section{Situaciones de riesgo en el entorno}

Así como la situación sociopolítica del país tiene incidencia en la salud mental de la población, también existen fenómenos propios del entorno en el que viven las personas, que pueden influir negativamente en su calidad de vida y su desarrollo: 470 (54.3 \%) adultos reportaron la presencia de delincuencia común en el entorno en el que viven; 419 (48.4\%) manifestaron la presencia de habitantes de calle; 368 (42.5\%) informaron que en su entorno existe el expendio de estupefacientes; 233 (26.9\%) reportaron la presencia de pandillas juveniles; 95 (11 \%) identificaron en su entorno otras ventas ilegales; 64 evidenciaron la presencia de algún grupo armado organizado al margen de la ley $(7.4 \%)$ y $19(2.2 \%)$ adultos señalaron otras situaciones de riesgo tales como el ejercicio de la prostitución, la presencia de inmigrantes, el consumo de alcohol y el consumo de estupefacientes.

\section{Maltrato y violencia familiar}

Frente a la frecuencia de conflictos al interior de la familia, 275 (31.7 \%) manifestaron tener conflictos en su familia algunas veces en los últimos doce meses, 244 (28.1\%) adultos reportaron tener conflictos en su familia algunas veces al mes; 172 (19.8 \%) identificaron conflictos en su familia algunas veces a la semana y 48 (5.5\%), una o más veces al día. Se indagó por 
la forma en como la población adulta soluciona los conflictos en familia, encontrándose que el $67.3 \%$ lo hace por medio del diálogo; el $32 \%$ evade la situación; en el $22.1 \%$, alguien toma las decisiones al interior de la familia y los demás lo siguen y el $9.1 \%$ soluciona los conflictos de manera violenta. En cuanto a las dinámicas de violencia que pueden presentarse al interior de las familias, 390 (45.5\%) adultos identificaron la presencia de uno o varios de los siguientes tipos de maltrato: 365 personas reportaron maltrato psicológico; 90, maltrato físico; 69, maltrato patrimonial y 22 , maltrato sexual.

Por otra parte, al indagar por la forma en que las personas suelen enfrentar situaciones de violencia que las involucra, los participantes reportaron una o varias de las siguientes: 289 (33.6 \%) adultos contestaron que "hacen de cuenta que no pasa nada y le restan importancia",189 (22\%) manifestaron que "a su vez se vuelven violentos", 165 (19.2\%) piensan que "su futuro es incierto y que encontrarán algo mejor en otro lugar" y 97 (11.3\%) "se quedan paralizados".

\section{Pérdidas y duelos}

La pérdida de personas significativas se constituye en un evento que produce un importante sufrimiento emocional y es un factor asociado al riesgo de problemas y trastornos mentales. Frente a las pérdidas sufridas en los últimos 12 meses, 139 personas refirieron haber perdido a su esposo/a o compañero/a; 117, familiares o parientes (incluidos hijos, nietos y hermanos); 57, amigos; 19, compañeros de trabajo o estudio y siete mencionaron haber experimentado otras pérdidas significativas tales como el consejero, el terapeuta, la mascota. En relación con el motivo de las pérdidas significativas, 103 adultos mencionaron como razón de la pérdida una ruptura de pareja; 76, la muerte; 17 se refirieron a una mudanza; 16, a una ruptura familiar y 31 a otro tipo de razones tales como dificultades relacionales, razones laborales, problemas de salud.
Motivos de consulta de la población adulta y aspectos clínicos asociados

De los 869 adultos que hicieron parte de este estudio, 811 (93\%) solicitaron atención individual y 58 (7 \%) solicitaron atención en pareja. Para los que pidieron atención individual, las dificultades emocionales y del estado del ánimo son el motivo de consulta más frecuente reportado en un $30.9 \%$ (76 hombres y 170 mujeres) de la población adulta. Este grupo se refirió a dificultades de índole cotidiana tales como frustraciones personales, académicas y laborales, baja autoestima, inseguridades, temores, entre otros. Se reportaron también síntomas clínicamente significativos como tristeza, ansiedad y pérdida del interés en actividades de la vida diaria. Entre los factores contextuales con los que los adultos relacionan la aparición de esta problemática, se mencionaron principalmente las dificultades con la familia, las dificultades de pareja y los problemas económicos.

El siguiente motivo de consulta reportado por un $18.9 \%$ (41 hombres y 112 mujeres) de los adultos, correspondió a las dificultades en las relaciones con el grupo primario de apoyo, entendido como relacionado con las personas más cercanas a los consultantes. Del total de 153 personas adultas, 54 manifestaron consultar por dificultades en las relaciones de pareja; 52 , en las relaciones familiares y 47 , en las relaciones paterno-filiales. En cuanto a los factores contextuales con los que relacionaron la aparición de la problemática, se reportaron situaciones traumáticas del pasado, problemas económicos y dificultades en el estudio y/o trabajo.

El tercer motivo de consulta más frecuente en adultos, fueron las dificultades relacionadas con pérdidas y situaciones de duelo, reportado por un $10.7 \%$ de los consultantes (25 hombres y 62 mujeres), quienes estaban atravesando una separación de pareja, rupturas familiares, duelos por muerte o por enfermedad. Entre los factores contextuales con los que relacionaron la aparición de la problemática, las personas 
de este grupo hicieron referencia a situaciones traumáticas del pasado, la presencia de problemas económicos y las dificultades en el estudio y/o trabajo.

El estudio permitió evidenciar otros motivos de consulta para la búsqueda de atención psicológica, como la presencia de un diagnóstico psicopatológico, la ideación y conducta suicida y la adaptación a nuevas situaciones vitales. Es fundamental mencionar que, del total de la población adulta que participó en el estudio, 186 $(24.1 \%)$ personas presentaban un diagnóstico previo que señalaba la presencia de alguna condición clínica psicopatológica.

En relación con el tiempo de ocurrencia, el momento vital en que la persona ubicaba el origen de la problemática y los tratamientos recibidos con anterioridad, se evidenció que el $57.9 \%$ de las personas adultas refirieron que habían transcurrido más de doce meses desde el momento de aparición de la problemática hasta el momento de la consulta; el 51.5 \% consideró que la problemática se originó en edades tempranas (niñez o adolescencia), el $47.5 \%$ había recibido previamente tratamiento psicológico, y el $25 \%$, tratamiento psiquiátrico.

Los motivos de consulta reportados por estas parejas se relacionan con dificultades en la interacción entre sus miembros (reportadas por 14 hombres y 12 mujeres); problemáticas relacionadas con los hijos (reportadas por tres hombres y tres mujeres); dificultades en la familia nuclear (reportadas por cuatro hombres y cuatro mujeres) y la presencia de violencia al interior de la familia (reportada por dos hombres y tres mujeres). Del total de personas que solicitaron atención en pareja, 25 refirieron la presencia de maltrato psicológico con una frecuencia alta de varias veces a la semana. Los problemas de comunicación, las dificultades económicas presentes, el maltrato intrafamiliar, las dificultades en relación con la familia extensa y la infidelidad, fueron aquellas situaciones identificadas por las parejas como generadoras de las principales dificultades.

\section{Consumo de sustancias psicoactivas}

Respecto al consumo de sustancias psicoactivas, la población de adultos que participó en el estudio reportó que, en los últimos doce meses, el alcohol fue la sustancia de mayor prevalencia de consumo presente en un $68.4 \%$ del total de consultantes. En cuanto a la frecuencia de consumo, el $63.5 \%$ refirió consumir algunas veces durante los últimos doce meses; el $29.7 \%$, algunas veces al mes y un $6.8 \%$, algunas veces a la semana. El cigarrillo es la siguiente sustancia de mayor consumo con el $24.7 \%$ en la población de adultos participantes del estudio. Este dato es seguido por el $13 \%$ de quienes reportaron consumo de sustancias psicoactivas y el 8.3 $\%$ que manifestaron consumir tranquilizantes/ estimulantes sin prescripción.

Ideación de muerte, daño a sí mismo y a otros, conducta suicida

Otro indicador clínico de importancia para valorar posibles complicaciones y riesgos en la salud mental de las personas, es la presencia de ideaciones de muerte, suicidio, daño a otros o a sí mismo y/o conductas de daño o suicida. En cuanto a la presencia de estas ideaciones, en los últimos doce meses, el $67.4 \%$ de la población adulta respondió afirmativamente a la presencia de uno o varios de estos pensamientos, distribuidos así: 393 personas (45.4\%) reportaron ideas sobre su propia muerte; 362 (41.8\%), sobre la muerte de personas cercanas; 173 (20\%), ideas suicidas; 164 (19 \%), ideas de daño a sí mismo/a; 139 (16.1\%) ideas de muerte de mascotas y 100 (11.6\%) ideas sobre causar daño o lesiones a otros. Además de ideaciones alrededor de la muerte, el $12 \%$ de los adultos reportó conductas de daño a sî mismo/a; el $6.9 \%$, intentos de suicidio y el $4.3 \%$ causaron daño o lesiones a otros en los últimos doce meses. De los que cometieron intentos de suicidio, el $42.3 \%$ tiene un antecedente de diagnóstico psicopatológico. En total, las personas que presentaron una o varias de estas 
conductas, representan el $17 \%$ del total de la población adulta que participó en el estudio.

Búsqueda de ayuda y expectativas frente al tratamiento

Al indagar por las personas o alternativas buscadas para intentar solucionar la situación que motivó la consulta, se evidenció que la familia, los amigos y los acompañantes espirituales son las personas a las que más se acerca la población adulta para intentar solucionar su problemática. Actividades como el deporte y la lectura de libros de autoayuda, constituyen otras herramientas utilizadas por los consultantes como alternativas de solución. Con respecto a las expectativas que tiene la población adulta frente a la intervención psicológica, estas están orientadas a obtener mayores niveles de bienestar, obtener orientación y apoyo y la resolución de una problemática particular.

\section{Resultados población adolescente}

\section{Características generales}

Del total de la muestra de adolescentes, el 58.6 $\%$ fue remitido por otro profesional o institución de salud, educación o de justicia, y el $41.4 \%$ tomó la decisión de asistir al psicólogo de manera voluntaria o por iniciativa de su familia. La Tabla 3 sintetiza las características generales de esta población.
Tabla 3

Características generales población adolescente

\begin{tabular}{lcc}
\hline \multicolumn{1}{c}{ Variable } & Frecuencia & $\%$ \\
\hline Sexo & & \\
\hline Varones & 110 & 46.2 \\
Mujeres & 128 & 53.8 \\
\hline Estudia actualmente & & \\
$\quad$ Sí & 220 & 92.4 \\
No & 18 & 7.6 \\
\hline Grado cursado & & \\
$\quad$ Básica Secundaria & 114 & 51.8 \\
$\quad$ Educación Media & 60 & 27.2 \\
$\quad$ Universidad & 44 & 20 \\
\hline Actividad laboral & & \\
$\quad$ Sí & 9 & 3.8 \\
$\quad$ No & 229 & 96.2 \\
\hline Personas a cargo & & \\
$\quad$ Sí & 12 & 5.2 \\
$\quad$ No & 220 & 94.8 \\
\hline
\end{tabular}

Factores de protección psicosocial y redes de apoyo

En relación con el número de personas con las que viven, 88 (37.1\%) adolescentes reportaron convivir con cuatro o más personas; 69 (29.1\%), con tres y $65(27.4 \%)$ con dos. La composición del hogar de los adolescentes encontrada en el estudio evidencia que en el $47.6 \%$ de los hogares se encuentran presentes ambos padres; en el 36.2 $\%$, solo la madre; en el $5.9 \%$ está presente solo el padre y el $11 \%$ de los adolescentes participantes del estudio viven con otros familiares como los abuelos. En cuanto a las entidades a las que se acude en busca de apoyo y asesoría, los resultados muestran que la población adolescente asiste principalmente a iglesias o congregaciones religiosas $(12.3 \%)$, seguidas de instituciones de apoyo a la familia $(8.5 \%)$ y de instituciones de justicia $(7.2 \%)$. Es pertinente anotar que un $72 \%$ de la población adolescente reportó no haber hecho uso de estos servicios. Se indagó también acerca de las personas a quienes se acude para obtener ayuda con los problemas. Al respecto, la tendencia indica que la población adolescente busca a los miembros de su familia (82.3\%), seguido de sus amigos (50.2\%) y la 
pareja $(17.7 \%)$. En el ámbito de las relaciones familiares, se tuvo en cuenta el reporte de las personas frente a factores como el apoyo que recibe frente a sus problemas y necesidades, la expresión de sentimientos, la disposición frente a nuevos proyectos y el tiempo que comparten juntos. En relación con lo anterior, 102 (42.8\%) adolescentes reportaron satisfacción alta con su familia, 118 (49.5\%), satisfacción media y 18 (7.5 $\%)$, baja satisfacción familiar.

Por último, en cuanto al uso del tiempo libre, los adolescentes reportaron una o varias de las siguientes actividades: actividades de ocio (leer, jugar videojuegos, ver televisión y navegar en internet) (80.2\%), actividades deportivas (41.8\%), actividades artísticas (31.2\%), actividades culturales (cine, música y museos) (27 \%), actividades sociales (voluntariados, trabajo comunitario y eventos religiosos) (21.5 \%). El $6.3 \%$ de la población adolescente indicó no realizar ninguna de las anteriores actividades.

Factores de riesgo psicosocial: afectación por el conflicto armado colombiano

Al indagar acerca de la relación experimentada por los adolescentes con el conflicto armado colombiano, se encontró que nueve de ellos manifestaron haber tenido una relación directa con este y se reconocían a sí mismos como víctimas. Estos adolescentes señalaron uno o varios de los siguientes hechos victimizantes: homicidio de familiares u otros significativos, en cuatro casos; desplazamiento forzado, en tres casos; atentados, en tres casos; experiencias de pérdida o destrucción de bienes materiales, en dos casos; amenazas, en dos casos; extorsiones, en dos casos; desaparición forzada, en un caso; secuestro, en un caso; masacre, en un caso; tortura, trato cruel, inhumano o degradante en un caso.

Frente a la afectación indirecta del conflicto armado en la vida de los adolescentes, 54 (24 $\%)$ consultantes respondieron afirmativamente a la hora de preguntarles por tales efectos. De esta población, 25 de ellos manifestaron "sentir miedo de convertirse en víctimas directas";
22 reportaron "sentir que nada de lo que hacían podía contribuir al cambio del país"; 12 mencionaron que "han dejado de expresar sus opiniones públicamente"; 12 "evitan las noticias sobre política u orden público"; 10 "han restringido la movilidad en el territorio nacional"; 10 "evitan pertenecer a grupos o participar en asuntos comunitarios"; siete consultantes "sienten poco impacto emocional en cuanto a las noticias relacionadas con el conflicto" y cuatro señalaron otros tipos de afectación.

\section{Situaciones de riesgo en el entorno}

En cuanto a las condiciones del contexto en las que vive la población de adolescentes que participó en el estudio, se evidenció que los consultantes identificaron la presencia de las siguientes situaciones de riesgo en su entorno: habitantes de calle, en 112 (47.7 \%) casos; delincuencia común, en 111(47.2 \%) casos; expendio de estupefacientes, en 95 (40.4\%) casos; pandillas juveniles, en 74 (31.5 \%) casos; otras ventas ilegales, en 25 (10.6\%); la presencia de un grupo armado organizado al margen de la ley, en ocho (3.4\%) casos y otras situaciones de riesgo como corrupción y prostitución, en tres $(1.3 \%)$ casos.

\section{Maltrato y violencia familiar}

Con referencia a la frecuencia de conflictos al interior de la familia, 78 (32.8\%) consultantes reportaron tener conflictos en su familia algunas veces al mes; 52 (21.8\%), algunas veces a la semana; 44 (18.5\%), algunas veces en los últimos doce meses y 19 (8 \%), una o más veces al día. En cuanto a la forma como se suelen solucionar los conflictos en su familia, las opciones más reportadas por los adolescentes fueron: "por medio del diálogo", referido por 174 (73.1 \%); "no se habla del tema", por 72 (30.3 $\%)$; "alguien toma la decisión y los demás lo siguen", señalado por 50 (21\%); "se solucionan de manera violenta", reportado por $18(7.6 \%)$ y "se acude a un tercero", referido por 14 (5.9\%) consultantes adolescentes. 
Por otra parte, al indagar por la forma en que las personas suelen enfrentar situaciones de violencia que las involucra, los adolescentes reportaron una o varias de las siguientes: 96 (40.3\%) jóvenes contestaron que "hacen de cuenta que no pasa nada y le restan importancia"; $59(24.8 \%)$, "darse cuenta del sufrimiento de los otros y tomar acciones solidarias"; 56 (23.5 \%) manifestaron que "a su vez se vuelven violentos"; 48 (20.2 \%) "buscar posibilidades vitales y creativas"; 26 (10.9\%) piensan que "su futuro es incierto y que encontrarán algo mejor en otro lugar" y 19 (8\%) "se quedan paralizados".

Pérdidas y duelos

Ante la pregunta por pérdidas significativas sufridas en los últimos 12 meses de su vida, se encontró que 66 adolescentes, del total de participantes, respondieron una o varias de las siguientes opciones: en 33 casos, la pérdida de familiares o parientes; en 30 casos, la pérdida significativa de amigos; en 15 casos, la pérdida de compañeros importantes de la escuela; en 12 casos, la pérdida del compañero/a o novia/o; en seis casos, la pérdida de vecinos. En relación con el motivo de las pérdidas significativas, 13 adolescentes mencionaron como razón de la pérdida, aspectos asociados al contexto escolar; 12 se refirieron a la muerte; ocho mencionaron situaciones de mudanza; seis se refirieron a dificultades relacionales; cinco manifestaron rupturas amorosas; cinco señalaron separaciones de los padres y cinco hicieron alusión a otras razones.

Motivos de consulta de población adolescente y aspectos clínicos asociados

El motivo de consulta más frecuente de la población de adolescentes consultantes fueron las dificultades emocionales y del estado del ánimo, reportado por el $18.1 \%$ (16 hombres y 27 mujeres) de los casos. Los adolescentes se refirieron a quejas concernientes al sentimiento de soledad, la sensación de inseguridad, apatía, ansiedad y afectos como la tristeza. Los factores contextuales con los que relacionaron la aparición de la problemática, se refieren a las dificultades en el estudio, la interacción con padres y el entorno social.

El siguiente motivo de consulta reportado como de mayor importancia fueron los problemas del comportamiento, con un $17.2 \%$ (28 hombres y 13 mujeres) del total de los casos. Este motivo de consulta se presentó en casos de adolescentes en los que se hizo evidente la dificultad para acatar normas sociales y familiares, problemas concernientes a la adaptación a diferentes entornos y en algunos casos la violación de los derechos de los otros. Los comportamientos disruptivos más frecuentes encontrados fueron la agresividad, la mentira y el robo. En cuanto a los factores contextuales con los que se relaciona la aparición de este motivo de consulta fueron las dificultades en la esfera académica y las dificultades con los padres ocuparon los primeros lugares de importancia.

El tercer motivo de consulta más reportado en el estudio fueron las dificultades en el aprendizaje y bajo rendimiento académico. Este motivo de consulta estuvo presente en un 10.9 $\%$ (19 hombres y 7 mujeres), del total de casos de adolescentes. Dichas problemáticas giran alrededor de fenómenos como el fracaso escolar y la obtención de calificaciones bajas. Los factores contextuales con los que relacionan la aparición de estos motivos de consulta son las interacciones con la familia, los padres o la evidencia de un problema de salud.

Otros motivos de consulta de menor aparición en la población de consultantes adolescentes fueron las dificultades en el grupo primario de apoyo y la presencia de un cuadro clínico psicopatológico. Es importante señalar que se evidenció que 54 adolescentes (23.5\%) participantes en el estudio, presentaban antecedentes de un diagnóstico clínico previo que puede indicar alguna condición psicopatológica presente antes de la consulta actual.

En relación con el tiempo de ocurrencia, el origen de la problemática y los tratamientos recibidos anteriormente, el $54.7 \%$ de los adolescentes reportaron que habían transcurrido 
más de doce meses desde el inicio de la problemática por la que consultaban en esta ocasión; el 40.7 \% consideraba que la misma se había originado en etapas anteriores de su vida -infancia o niñez-; el 50 \% había recibido antes tratamiento psicológico y el $18.2 \%$, tratamiento psiquiátrico.

\section{Consumo de sustancias psicoactivas}

El estudio indagó acerca del consumo de sustancias psicoactivas y su frecuencia en la población de adolescentes consultantes. Los resultados evidenciaron que la sustancia psicoactiva de mayor consumo en esta población es el alcohol, en un $39 \%$ del total de los casos. En cuanto a la frecuencia del consumo de alcohol "algunas veces durante los últimos doce meses", 70 adolescentes señalaron esta opción; 17 manifestaron que consumían alcohol "algunas veces al mes" y cuatro, "algunas veces a la semana".

La segunda sustancia reportada como de mayor consumo por parte de la población de adolescentes, fue el cigarrillo. El 11.9 \% reportó que había consumido cigarrillos en los últimos doce meses. Por otro lado, y al indagar por otras sustancias psicoactivas, $10.1 \%$ manifestó haber consumido otras sustancias psicoactivas y un $5 \%$ refirió haber consumido tranquilizantes/ estimulantes sin prescripción.

Ideación de muerte, de daño a sí mismo y/o a otros, conducta suicida

Un tema muy sensible para la salud mental de los adolescentes es la presencia de ideaciones de muerte y /o daño. Los resultados de este estudio encontraron la presencia de ideación de muerte de personas cercanas en 78 jóvenes $(33.1 \%)$ de la población de consultantes adolescentes; ideas acerca de su propia muerte en 77 del total de los casos $(32.6 \%)$; ideas de muerte de mascotas en 48 (20.3\%); ideas de daño a sí mismo/a en 46 (19.5\%); ideas de daño o lesiones a otros en 34 (14.4\%) y 30 adolescentes consultantes (12.7\%) reportaron ideaciones suicidas activas. En cuanto a la presencia de antecedentes de conducta suicida y daño a sí mismo o a otros en los últimos doce meses, 45 adolescentes consultantes (19.2\%) reportaron daño a sí mismo/a durante este periodo de tiempo; 23 adolescentes (9.8\%) manifestaron la presencia de conductas de daño o lesiones a otros durante este periodo de tiempo y 21 jóvenes (9\%) refirió antecedentes de uno o varios intentos de suicidio durante los últimos doce meses.

De los 21 adolescentes que tienen antecedente de conducta suicida, 13 de ellos reportaron un diagnóstico clínico psicopatológico previo. A la hora de indagar por los factores contextuales e individuales de riesgo que podrían estar relacionados con estos comportamientos, los conflictos familiares y la pérdida de una relación significativa son las principales situaciones presentes informadas por la mayoría de estos adolescentes.

Búsqueda de ayuda y expectativas frente al tratamiento

$\mathrm{Al}$ indagar por las personas o alternativas buscadas para intentar solucionar la situación que motivó la consulta, se evidenció la siguiente tenencia: la familia (64\%), los amigos (33.9 $\%)$ y profesores $(24.6 \%)$ son las personas a las que más se acerca la población adolescente para intentar solucionar su problemática. Por otro lado, terapias ocupacionales y del lenguaje (12.3 $\%)$ y el uso de medicamentos prescritos (10.2\%), constituyen otras herramientas utilizadas por los consultantes como alternativas de solución. En cuanto a las expectativas que tiene la población adolescente frente a la atención psicológica, los adolescentes consultantes mencionaron la búsqueda de mayores niveles de bienestar (49.4 \%); la obtención de orientación y apoyo (46.8 $\%$ y y la resolución de una problemática particular (45.1\%). 
Resultados población infantil

\section{Características generales}

Del total de la población infantil que participó en el estudio, el $64.3 \%$ de los menores fue remitido a psicología por una institución: en la mayoría de los casos se trató del colegio o escuela en la que estudiaban y en el $35.7 \%$ de los casos fueron los adultos responsables de los menores quienes solicitaron la atención psicológica.

Tabla 4

Características generales Población Infantil

\begin{tabular}{lcc}
\hline \multicolumn{1}{c}{ Variable } & Frecuencia & $\%$ \\
\hline Sexo & & \\
$\quad$ Varones & 276 & 66 \\
$\quad$ Mujeres & 142 & 33.9 \\
\hline Estudia actualmente & 410 & 98.8 \\
$\quad$ Sí & 8 & 1.2 \\
$\quad$ No & 316 & 77.6 \\
\hline Grado cursado & 44 & 10.8 \\
$\quad$ Básica Primaria & 46 & 11.3 \\
$\quad$ Preescolar & & \\
Básica Secundaria & 246 & 60.7 \\
Institución a la que asiste & 126 & 31.1 \\
$\quad$ Escuela o colegio público & 4 \\
Escuela o colegio privado & 16 & 4 \\
Guardería o jardín privado & 15 & 3.7 \\
$\quad$ Guardería o jardín público & 15 \\
$\quad$ Hogar comunitario & 1 & 0.2 \\
\hline
\end{tabular}

Aspectos psicosociales relacionados con la salud mental. Factores de protección psicosocial y redes de apoyo

En cuanto a la conformación de las familias de los niños, 184 (44.3\%) viven con cuatro o más personas; $131(33.5 \%)$ con tres personas; 80 $(19.2 \%)$ con dos personas y 20 (4.8 \%) con una sola persona. La composición del hogar de los niños encontrada en el estudio evidencia que en el $47.9 \%$ de los hogares se encuentran presentes ambos padres; en el $38.5 \%$, solo la madre; en el $6 \%$, está presente solo el padre y el $7.4 \%$ de los niños participantes del estudio viven con otros familiares o en hogares de protección, separados parcial o totalmente de sus padres.
$\mathrm{Al}$ explorar acerca de las personas a las que el niño/a suele acudir cuando requiere ayuda de un adulto, los cuidadores responsables de los menores manifestaron que en $342(82.2 \%)$ casos, el menor busca a la madre; en 185 (44.5\%), al padre; en 156 (37.5\%), a los abuelos; en 96 (23.1 $\%)$ casos el niño cuenta con los tíos y en 83 (20 \%) los menores recurren a sus hermanos.

$\mathrm{Al}$ indagar por las personas con quiénes los niños/as comparten la mayor parte del tiempo cuando se encuentran fuera de la institución escolar, se encontró que en 241 (57.9 \%) casos los menores se encuentran con la madre; en 114 (27.4\%), se encuentran en casa bajo el cuidado de un miembro del hogar; en 73 (17.5\%), los menores se encuentran en casa al cuidado de familiares; en 69 (16.6\%), el menor se encuentra con el padre. En 10 (2.4 \%) casos, los acudientes reportaron que los niños se encuentran solos en casa.

Las actividades recreativas que los niños y las niñas llevan a cabo son compartidas principalmente con la madre en 270 (64.7 $\%)$ casos; en 155 (37.2\%), este tiempo de actividades son compartidas principalmente con el padre; en 148 (35.5\%), las actividades recreativas se llevan a cabo con los hermanos; en $88(21.1 \%)$, la recreación se lleva a cabo con los abuelos; en 79 (18.9 \%), la recreación se lleva a cabo con los primos y en 70 (16.8\%) casos los espacios de recreación son compartidos con amigos. Las actividades recreativas en las que los menores ocupan estos espacios son principalmente la televisión, el juego en la casa, las actividades lúdicas fuera de la casa y la navegación en internet, leen libros.

En relación con la forma en que se solucionan los conflictos al interior de la familia, las opciones reportadas fueron las siguientes: "por medio del diálogo", en 326 casos (79.3 \%); "no se habla del tema", en 73 casos de menores (17.8\%); "alguien toma la decisión y los demás siguen a esta persona", fue la opción evidenciada en 65 casos de menores (15.8\%); "de manera violenta", en 46 casos (11.2\%) y "se acude a un tercero" en 44 casos de menores (10.7\%). 
Estresores psicosociales y factores de riesgo. Situaciones de riesgo en el entorno

El estudio indagó por las condiciones del contexto en el que vive la población infantil consultante. Frente a lo anterior, sus acudientes y acompañantes por vez primera al servicio de atención psicológica universitario, identificaron la presencia de una o varias de las siguientes situaciones de riesgo: delincuencia común, en 138 casos; habitantes de calle, en 129 casos; pandillas juveniles, en 109 casos; expendio de estupefacientes, en 103 casos; otras ventas ilegales, identificadas en 21 casos; grupos armados organizados al margen de la ley, en 19 casos y otras situaciones de riesgo como consumo de alcohol, consumo de estupefacientes, extorsión, inmigrantes y la presencia de perros peligrosos, en siete casos del total de participantes en el estudio.

\section{Conflicto al interior de la familia}

Al explorar la presencia de conflictos en la familia del niño/a, en 97 (23.4\%) casos se reportó la presencia de conflictos al interior de la familia algunas veces al mes; en 96 (23.2 $\%)$, los conflictos se presentan algunas veces durante los últimos doce meses; en 93 (22.5 $\%)$, los acudientes manifestaron que al interior de las familias de los menores no se presentan conflictos; en 82 (19.8\%), se reportó que los conflictos familiares ocurren algunas veces a la semana y en 38 (9.2\%) casos, los conflictos familiares tienen lugar una o más veces al día.

\section{Pérdidas y duelos}

Como otro factor de riesgo identificado en la infancia, se reportó que 159 (38.3 \%) niños/ as, perdieron alguna relación importante en los últimos 12 meses. De esta población de menores, $102(67.1 \%)$ se refirieron a la pérdida de familiares o parientes; 71 (46.7 \%) hicieron referencia a amigos o compañeros de escuela y $31(20.4 \%)$ de los menores manifestaron haber perdido otras figuras significativas tales como profesores, padrastros o sus mascotas.

En relación con el motivo de las pérdidas significativas, 34 acudientes de los menores refirieron la separación de los padres como razón; 33 mencionaron mudanzas; 23 reportaron la muerte de familiares diferentes a los padres; 20 señalaron razones asociadas al contexto escolar; seis indicaron abandono paterno, cuatro mencionaron problemas de salud física; tres refirieron migración; uno mencionó la muerte de la madre y 12 esgrimieron otras razones como cambio de hogar sustituto, pérdida de la custodia, separación del hogar biológico, privación de la libertad de alguno de los padres, entre otros.

\section{Motivos de consulta de población infantil y aspectos clínicos asociados}

El motivo de consulta más reportado por la población infantil participante del estudio, fueron los problemas del comportamiento, presentes en el $31.6 \%$ (34 niñas y 98 niños) del total de los casos. Quienes consultaron por estas problemáticas, hicieron referencia a dificultades presentes tales como conductas agresivas, inquietud motora, ausencia de seguimiento a instrucciones del adulto y mentiras.

El siguiente motivo de consulta más informado en la población de menores participantes en el 17.7 \% (27 niñas y 47 niños) de los casos, fueron las dificultades en el aprendizaje y la solicitud de estudio y medición del coeficiente intelectual del niño/a. Los acompañantes consultaban con una demanda de evaluación psicológica infantil, por la sospecha de la presencia de un déficit cognitivo, por preocupaciones alrededor del bajo rendimiento académico y desinterés asociado y por dificultades en la adquisición y el desarrollo de habilidades específicas tales como la lectura y/ o la escritura.

El tercer motivo de consulta más reportado en los menores participantes del estudio, fueron las dificultades emocionales y del estado del ánimo, presentes en el $10.3 \%$ (21 niñas y 22 niños) del total de los casos de menores. Las características principales evidenciadas en dichos 
niños/as hacen referencia a llanto frecuente, la presencia de múltiples miedos, irritabilidad y aislamiento. Otros motivos referidos por los acompañantes de los niños/as fueron: dificultades en el desarrollo, dificultades en las relaciones paterno-filiales y dificultades familiares. Los acudientes responsables de los menores también identificaron, en algunos de los casos, antecedentes de retraso o dificultades en el desarrollo, específicamente en patrones de adquisición del lenguaje, de control de esfínteres y en logros del desarrollo y adquisiciones tales como gatear y caminar.

En relación con el tiempo de ocurrencia de la problemática y los tratamientos recibidos anteriormente, el $64.1 \%$ de los casos de la población infantil reportó que habían transcurrido más de doce meses desde el inicio de la problemática por la que consultaban en esta ocasión, el 41.4 \% había recibido antes tratamiento psicológico y el $9.9 \%$, tratamiento psiquiátrico.

Ideación de muerte, ideas de daño a sí mismo y/o a otro, conducta suicida

Los acudientes de los menores también se refirieron a la presencia de ideación de muerte, en algunos de los casos de niños y niñas que acudían por vez primera a los centros de atención psicológica universitarios. El reporte que realizaron en las consultas de primera vez es el siguiente: en 68 (16.5\%) casos, los menores habían manifestado ideas sobre la muerte de personas cercanas; en 66 (16.1 \%), habían manifestado ideas sobre su propia muerte; en $44(10.7 \%)$ del total de los casos de menores, estos se habían referido a ideas sobre daño a sí mismo/a; en 41 (10\%), los menores habían hecho alusión a causar daño o lesiones a otros; en 37 (9\%), estos se habían referido a ideas sobre la muerte de mascotas y en 26 (6.3 \%) casos han expresado ideas sobre suicidio. Del total de los niños y niñas participantes del estudio, 55 (13.8\%) han causado daño o lesiones a otros; $40(10 \%)$ daño a sí mismos y nueve (2.3 \%) cometieron intentos de suicidio en el último año.
Las edades de los menores (cuatro hombres y cinco niñas) que presentaron conductas suicidas, se encuentran comprendidas entre los 6 y los 12 años.

\section{Búsqueda de ayuda y expectativas frente al tratamiento}

La búsqueda de ayuda y alternativas de apoyo para la solución de la problemática reportadas por los acudientes de los menores, evidencia que los profesores (51.9\%), la familia (49\%) y los amigos (12.4\%) son las personas a las que más tienden a acudir. Por otro lado, la búsqueda de modalidades terapéuticas $(31.3 \%)$ \#como la terapia ocupacional, del lenguaje, entre otras\# y la actividad física $(21.8 \%)$ son las actividades y apoyos a los que tienden a acudir en la búsqueda de soluciones a problemáticas consideradas específicas. En cuanto a las expectativas que tienen los acudientes frente a la intervención psicológica, estos expresan una o varias de las siguientes alternativas: obtener orientación y apoyo, en $77.8 \%$ de los casos; resolver una problemática particular, en $53 \%$ de los casos y el cambio del comportamiento en el niño, en 52.8 $\%$ de los casos.

\section{Discusión}

El estudio sobre la caracterización psicosocial y de los motivos de consulta de la población que asiste a 28 Centros de Atención Psicológica Universitarios, ha permitido conocer más de cerca las demandas y necesidades de atención psicológica y en salud mental de niños y niñas, adolescentes y adultos.

La psicoterapia resulta ser una elección de primera línea para la población a la hora de buscar apoyo para sus problemas en torno a la salud mental, tal y como lo muestra la Encuesta Nacional de Salud Mental (2015). Las expectativas de la población consultante en cuanto a la atención psicológica son expresadas de manera clara: la búsqueda de un mayor bienestar para sus vidas, la consecución de 
orientación y apoyo y el cambio en las dificultades que motivaron la consulta.

$\mathrm{Al}$ analizar con detenimiento las características psicosociales y los motivos de consulta de la población del estudio, es posible concluir que existen campos de trabajo prioritarios que deben ser tenidos en cuenta a la hora de diseñar estrategias de evaluación e intervención clínica y psicosocial. Estos comparten la visión de la Política Nacional de Salud Mental adoptada a partir del 7 de noviembre de 2018, y se exponen a continuación.

Uno de los resultados más importantes del estudio es aquel que nos permite ubicar a la familia como la red de apoyo más relevante para los niños, niñas, adolescentes y adultos. En esta medida, se plantea la importancia de trabajar en torno al fortalecimiento de las familias y sus lazos afectivos, así como el cuidado mutuo. Fue posible evidenciar que las comunicaciones familiares, la búsqueda de espacios de diálogo y la reflexión acerca de los conflictos requieren de estrategias de atención psicológica. Asimismo, las violencias familiares \# uno de los aspectos destacados del estudio\# permiten entrever la necesidad urgente de situarlas en una agenda psicológica que intervenga con acciones para afrontarlas, pensarlas, elaborarlas y repararlas.

Tanto en la población de adultos como en la de adolescentes, niñas y niños, fue posible identificar uno o varios duelos que hacen parte de la historia de vida de las personas que consultan los servicios psicológicos: las separaciones familiares, la pérdida de vínculos significativos, el desarraigo de colectivos y la muerte fueron algunas de las manifestaciones más importantes en las que tomaron forma estos relatos de ausencia. Las pérdidas han sido asociadas con problemas y trastornos mentales en población general (Londoño et al., 2010; Ministerio de Salud y Protección Social, 2015). A partir de estos hallazgos, es pertinente señalar la necesidad de trabajar las características específicas de las pérdidas, sus efectos emocionales y posibilidades de elaboración; a la vez, la comprensión de los duelos, no como un hecho aislado en la vida de una persona, sino como una cadena en la que se han podido experimentar una o más pérdidas.
Además del reporte de algunas personas que se consideran víctimas directas del conflicto armado en nuestro país, en el presente estudio y otros similares (Ministerio de Salud y Protección Social, 2015) se constituye en una señal de alarma los efectos que tiene el conflicto armado en la población colombiana que no se considera como una víctima directa: sentimientos de impotencia y desesperanza frente a lo que cada ciudadano puede hacer por su colectivo, la evasión de noticias sobre el conflicto, el sentimiento reiterativo de miedo al otro o a lo desconocido, el temor a movilizarse libremente por el territorio nacional y la reducción de la participación social y política activa, son algunos de los efectos que fueron identificados en la población de adultos y adolescentes participantes en esta investigación. Al tener en cuenta lo anterior y de acuerdo con los hallazgos del estudio, se propone que la intervención psicológica incluya elementos tales como la expresión de las emociones y la resonancia emocional con el otro, la aceptación y humanización del otro, el desarrollo de la empatía, la comprensión del miedo, la reflexión sobre los sentimientos de venganza y la capacidad de cambio de sí mismo y del colectivo. El marco de tales intervenciones debe abarcar el fortalecimiento de los lazos sociales y la confianza mutua.

El estudio permitió identificar factores de riesgo en el entorno cercano que traen consigo la sensación de vulnerabilidad para los sujetos en sus espacios de desarrollo vital: violencias, pandillismo y hurto, fomentan relaciones de desconfianza y miedo en los entornos de convivencia inmediata. Frente a lo anterior, las recomendaciones en cuanto a la atención psicológica implican la búsqueda de la potenciación del diálogo y la participación en proyectos que involucren el colectivo cercano, además de la valoración de la comunidad como red de apoyo ampliada para el cuidado de sí mismo y de los otros.

También, fue posible identificar que la mayoría de los niños que acuden a los centros psicológicos universitarios, son remitidos por una persona que hace parte del entorno escolar del menor. 
En el caso de los adolescentes, se encontró que los profesores son uno de los principales referentes para discutir sus problemáticas. Es por esto que se hace necesario el trabajo desde la psicología con los profesionales de las instituciones educativas, para concebir planes de acción en torno a la prevención y promoción de la salud mental, en aspectos tales como: las actividades de desarrollo de la empatía y la identificación de las violencias al interior de la institución escolar, la identificación de las características de bienestar en niños y niñas en el medio escolar, la comprensión de los problemas de comportamiento y de aprendizaje desde una visión más amplia de la salud mental, el desarrollo de herramientas para el acompañamiento psicoafectivo de los menores, el trabajo en torno a la inclusión de personas con capacidades diversas adentro y afuera del aula, la identificación temprana de dificultades y la remisión oportuna a servicios de atención primaria en salud mental y la inclusión de los padres y el diseño de espacios de psicoeducación.

Los hallazgos del estudio muestran que las cifras de consumo de sustancias\#alcohol y tabaco\# son inquietantes. En este sentido, se hace necesario continuar avanzando en los programas de prevención del consumo temprano de alcohol y tabaco, además de la urgencia de concebir planes y proyectos para el tiempo libre, la salud y la recreación en la población de adolescentes y adultos.

El daño a otros y a sí mismo, junto con la detección de la ideación suicida, constituyen unos de los datos más alarmantes que permitió identificar el presente estudio, al igual que lo evidenciado en estudios similares con población adulta y adolescente (Ministerio de Salud y Protección Social, 2015). La presencia de ideación de muerte en niños, adolescentes y adultos, relacionada consigo mismo o con terceros, se erige como una señal de alarma grave para la población atendida en los centros psicológicos universitarios, y amerita atención en salud mental de carácter prioritario por parte de profesionales de la psicología clínica y de la psiquiatría. La prevención primaria e identificación del daño en niños, adolescentes y adultos, la atención clínica individual y familiar, el fortalecimiento de los lazos afectivos seguros y la elaboración de experiencias y emociones intensas, son algunas de las directrices que sería posible trazar de acuerdo con los resultados del estudio.

Las dificultades emocionales y del estado de ánimo fueron el principal motivo de consulta evidenciado en la población de adolescentes y adultos participantes del estudio. Este hallazgo va en la misma línea de estudios anteriores que muestran la presencia de síntomas afectivos en personas que han sufrido pérdidas y presentan otros riesgos psicosociales (Espinosa et al., 2015; Londoño et al., 2010; López-Jaramillo et al., 2012). Entre las dificultades emocionales y del estado de ánimo se destacan los sentimientos de tristeza, soledad y la ansiedad. Por otro lado, casi la mitad de la población que solicitó atención psicológica en el período comprendido por este estudio, había acudido previamente a atención psicológica o psiquiátrica. Este punto resulta fundamental dentro de estas conclusiones, puesto que evidencia la necesidad de propuestas integrales en salud mental, convivencia y bienestar, que redunden en la conformación de redes de apoyo que, afectivamente, sean cercanas a las personas afectadas. Por otro lado, requiere de intervenciones clínicas, psicosociales y de equipos interdisciplinarios para la recuperación del bienestar de los adultos y los menores.

El estudio permite comprender que, de acuerdo con las necesidades de la población y sus demandas específicas para la consecución de su bienestar, la intervención psicológica debe construirse desde vértices que privilegien las características específicas del individuo, su familia o colectivo. El desarrollo de elementos como la creatividad y la curiosidad proporciona una mirada más profunda y compleja acerca de las alternativas y herramientas de apoyo que el individuo puede aportar y encontrar para sí mismo.

Los Centros de Atención Psicológica Universitarios tienen, por su propia naturaleza, un alcance limitado. Sin embargo, hemos comprobado a lo largo de los años que el acompañamiento psicológico que se da en el 
momento apropiado puede ser de gran utilidad para el bienestar integral de las personas. Tener una visión global de los motivos por los cuales las personas buscan ayuda es fundamental no solo en términos epidemiológicos, también clínicos, y básico para la implementación de estrategias de prevención y promoción de la salud mental.

A manera de recomendación para futuros estudios, advertimos la importancia de fortalecer la adecuada recolección de los motivos de consulta de la población que asiste a los Centros de Atención Psicológica Universitarios. En el presente estudio, el $9.7 \%$ de los motivos de consulta de la población adulta, el $12.6 \%$ de la población adolescente y el $5 \%$ de la población infantil no fue posible categorizarlos, debido a que no aportaban información suficiente. Teniendo en cuenta que el motivo de consulta es esencial para orientar la activación de rutas de atención y la asignación de profesionales al interior de los Centros, la capacitación en esta tarea y su supervisión resultan fundamentales para una adecuada recolección. Otra recomendación que se desprende de este estudio es buscar ampliar la cobertura de las investigaciones y de la atención misma que ofrecen los Centros a poblaciones afro, indígena, LGBTI y en condición de discapacidad.

Por último, se sugiere que se lleven a cabo periódicamente este tipo de estudios al interior de los Centros de Atención Psicológica Universitarios, con el fin de obtener información necesaria para apoyar los procesos de calidad de la atención en salud mental, orientar el diseño de estrategias de evaluación e intervención, identificar los motivos de mayor consulta y desarrollar guías de atención para los mismos, orientar preguntas de investigación focalizadas en problemáticas relevantes y generar bases de datos en red, a nivel local, regional y nacional, que contribuyan a visibilizar a la población y sus necesidades, así como incidir en la política pública.

\section{Agradecimientos}

Este estudio fue financiado por la Pontificia Universidad Javeriana, sede Bogotá, a través de Proyectos de Contribución de las facultades en el marco de la Planeación Universitaria 2021.

Agradecemos a María Fernanda Ramírez, Natalia Bettancourt, Sebastián Aponte y María Fernanda Parra, quienes participaron como asistentes en todas las fases y productos del proyecto.

Fueron asesores los profesores de la Facultad de Psicología de la Pontificia Universidad Javeriana, Sede Bogotá: Claudia Tovar Guerra, Alicia Durán Echeverri, Carolina Morales Arias y Liz Arévalo Naranjo, a quienes agradecemos su interés e importantes aportes.

Las universidades aliadas y colaboradoras con el estudio fueron: Universidad de la Sabana, Universidad Santo Tomás, Universidad Católica de Colombia, Universidad del Bosque, Universidad Piloto de Colombia, Fundación los Libertadores, Universidad San Buenaventura Medellín, Universidad de Envigado, Universidad Pontificia Bolivariana Medellín, Universidad Católica de Oriente, Católica del Norte Fundación Universitaria, Universidad CES, Universidad de la Costa, Universidad del Norte, Universidad Metropolitana, Corporación Universitaria del Caribe, Universidad Surcolombiana, Universidad de Ibagué, Universidad Antonio Nariño Ibagué, Fundación de Estudios Superiores Monseñor Abraham Escudero Montoya (Espinal), Universidad Católica de Pereira, Universidad de Manizales, Universidad San Buenaventura (Armenia), Universidad Pontificia Bolivariana (Palmira), Universidad San Buenaventura (Cali), Universidad Pontificia Bolivariana (Bucaramanga).

\section{Referencias}

Arroyave, G. (2002). Guía de orientaciones
para atención en salud mental y
trabajo psicosocial a la población
desplazada en Colombia. Recuperado

| Universitas Psychologica | V. I8 | No. 4 | 2019 | 
de http://www.disasterinfo.net/desplazados /documentos/avre/2003/guiaatpsico/guiaat encionpsicosocial.pdf

Beckham, E., \& Leber, W. (1997). Handbook of depression (2. ${ }^{\mathrm{a}}$ ed.). Nueva York: Guilford.

Bezanilla, J. M., Miranda, M. A., Valdez, C., Viveros, M., Rivera, R., Botello, F., \& López, J. (febrero, 2017). Construcción de un modelo mexicano de atención psicosocial. Trabajo presentado en el XVIII Congreso Virtual Internacional de Psiquiatría. Recuperado de http://psiqu.co $\mathrm{m} / 1-7770$

Caballero, L., Bobes, J., Vilardaga, I., \& Rejas, J. (2009). Prevalencia clínica y motivo de consulta en pacientes con trastorno de ansiedad generalizada atendidos en consultas ambulatorias de psiquiatría en España. Actas Españolas de Psiquiatría, 37(1), 17-20. Recuperado de https://www.actaspsiquiatria.es/reposito rio/10/55/ESP/12816+7-1258.pdf

Cáceres, D., Salazar, I. C., Varela, M. T., \& Tovar, J. R. (2006). Consumo de drogas en jóvenes universitarios y su relación de riesgo y protección con los factores psicosociales. Universitas Psychologica, 5(3), 521-534. Recuperado de https://revistas.javeriana.ed u.co/index.php/revPsycho/article/view/458

Calsina-Berna, A., Moreno Millán, N., GonzálezBarboteo, J., Solsona Díaz, L., \& Porta Sales, J. (2011). Prevalencia del dolor como motivo de consulta y su influencia en el sueño: experiencia en un centro de atención primaria. Atención Primaria, 43(11), 568-576. Recuperado de https://me des.com/publication/69717

Campodónico, N. (2018). Síntoma y demanda psicológica en el primer nivel de atención en la ciudad de la Plata. Perspectivas en Psicología, 15(1), 75-85. Recuperado de http://www.seadpsi.com.ar/revistas/inde x.php/pep/article/view/358

Clark, D. A., Beck, A. T., \& Alford, B. A. (1999). Scientific foundations of cognitive theory and therapy of depression. Nueva York: Wiley.

de la Portilla Maya, S., Montoya Londoño, D. M., Dussán Lubert, C., \& López Jaramillo,
M. R. (2016). Caracterización de los asistentes al centro de atención psicológica de la Universidad de Manizales. Hacia la Promoción de la Salud, 21 (2), 127-141. http s://doi.org/10.17151/hpsal.2016.21.2.10

de Miguel-Álvaro, A. (2018). iExiste relacio\#n entre el motivo de consulta que aportan los pacientes y el diagno\#stico cli\#nico? [Edición especial]. Psychologia Latina, 84-86. Recuperado de https://psicologia.ucm.es/data/cont/docs /29-2019-02-15-de\%20Miguel\%20\%C3\%8 1lvaro.pdf

Escobar-Pérez, J., \& Cuervo-Martínez, Á. (2008). Validez de contenido y juicio de expertos: una aproximación a su utilización. Avances en Medición, 6(1), 27-36. Recuperado de http://www.humanas.unal.edu.co/psico metria/files/7113/8574/5708/Articulo3_Jui cio_de_expertos_27-36.pdf

Espinosa Muñoz, M. C., Orozco Ramírez, L. A., \& Ybarra Sagarduy, J. L. (2015). Síntomas de ansiedad, depresión y factores psicosociales en hombres que solicitan atención de salud en el primer nivel. Salud Mental, 38(3), 201-208. https:// doi.org/10.17711/SM.0185-3325.2015.028

Gómez, M. L. (2010). Estudio descriptivo sobre las prácticas de atención psicológica en pacientes con psicosis tratados en instituciones de salud mental de Bogotá. Acta Colombiana de Psicología, 13 (1), 43-53. Recuperado de http://www.scielo.org.co/pd f/acp/v13n1/v13n1a05.pdf

Gómez, M., \& Pérez, E. (2017). Particularidades de los motivos de consulta psicológica de los estudiantes que asisten a la Dirección de Bienestar Universitario, Universidad de Antioquia. Revista de Psicología Universidad de Antioquia, 9(1), 75-92. https://doi.org/10 .17533/udea.rpsua.v9n1a06

González-Villalobos, J., \& Marrero, R. (2017). Determinantes sociodemográficos y personales del bienestar subjetivo y psicológico en población mexicana. Suma Psicológica, 24(1), 59-66. https://doi.org/10. 1016/j.sumpsi.2017.01.002 
Juárez, A. (2004). Factores psicosociales relacionados con la salud mental en profesionales de servicios humanos en México. Ciencia y Trabajo, 6(14), 189-196. Recuperado de https://pesquisa.bvsalud.org /ripsa/resource/pt/lil-420806

Labrador, F. (2010). Demanda de atención psicológica en la práctica clínica: tratamientos y resultados. Psicothema, 22 (4), 619-626. Recuperado de http://www .psicothema.com/psicothema.asp? $\mathrm{id}=3776$

Londoño, N. H., Marín, C. A., Juárez, F., Palacio, J., Muñiz, O., Escobar, B.,... López, I. C. (2010). Factores de riesgo psicosociales y ambientales asociados a trastornos mentales. Suma Psicológica, 17(1) 59-68. Recuperado de http://www.scielo.or g.co/pdf/sumps/v17n1/v17n1a5.pdf

López-Jaramillo, M. R., Montoya Londoño, D. M., \& Dussán Lubert, C. (2012). Caracterización de los asistentes al centro de atención psicológica de la Universidad de Manizales, 2006-2010. Hacia la Promoción de la Salud, 17(2), 149-166. Recuperado de http://www.scielo. org.co/pdf/hpsal/v17n2/v17n2a11.pdf

Maroto-Vargas, A., Molina-Fallas, L., \& Prado-Calderón, J. (2017). Características sociodemográficas y motivos de consulta de las personas atendidas en el Centro de Atención Psicológica de la Universidad de Costa Rica (2004-2013). Revista Costarricense de Psicología, 36(1), 23-44. htt ps://doi.org/10.22544/rcps.v36i01.02

Miller, L. A., \& Lovler, R. L. (2015). Foundations of Psychological Testing: A Practical Approach (5a Ed.). Nueva York: Sage.

Ministerio de Salud y Protección Social. (2015) Encuesta Nacional de Salud Mental. Recuperado de https://www.javerianacali.edu.co/sites/u jc/files/node/field-documents/field_docum ent_file/saludmental_final_tomoi_color.pd $\mathrm{f}$

Ministerio de Salud y Protección Social. (2017). Protocolo de atención integral en salud con enfoque psicosocial. Recuperado de https://w ww.minsalud.gov.co/sites/rid/Lists/Bibliote
caDigital/RIDE/DE/PS/Protocolo-de-atenc ion-integral-en-salud-papsivi.pdf

Ministerio de Salud y Protección Social. (2018). Política Nacional de Salud Mental. Recuperado de https://www.minsalud.gov.c o/Normatividad_Nuevo/Resoluci\%C3\%B3 n\%20No.\%204886\%20de\%202018.pdf

Narváez, N., \& Aguirre, H. (2016). Análisis de las impresiones diagnósticas en consultantes de un Centro de Atención Psicológica Universitario. Informes Psicológicos, 16(2), 87-101. https:// doi.org/10.18566/infpsicv16n2a06

Obando-Posada, D., Romero-Porras, J., Trujillo-Cano, A., \& Prada-Mateus, M. (2017). Estudio epidemiológico de salud mental en población clínica de un centro de atención psicológica. Psychologia, 11(1), 85-96. Recuperado de http://www.scielo.org.co/pdf/psych/v11n 1/1900-2386-psych-11-01-00085.pdf

Organización Mundial de la Salud. (2013). Plan de acción sobre salud mental 2013-2020. Recuperado de https://www.who.int/menta 1_health/publications/action_plan/es/

Ponce, M. (2016). Variedades de la demanda terapéutica en el contexto de atención primaria en Ejutla, Jalisco. Redes. Revista de Psicoterapia Relacional e Intervenciones Sociales, 34, 81-92. Recuperado de http://redesdigital.com.mx/ index.php/redes/article/view/190/0

Quesada, S. (2004). Estudio sobre los motivos de consulta psicológica en una población universitaria. Universitas Psychologica, 3(1), 7-16. Recuperado de http://www.redalyc.or $\mathrm{g} / \mathrm{html} / 647 / 64730102 /$

Sosa, J., Romero, M., Blum, B., Zarco, V., \& Medina-Mora, M. (2018). Programa de orientación y atención psicológica para jóvenes universitarios de la UNAM: Características de la población que solicita sus servicios. Revista Electrónica de Psicología Iztacala, 21(2), 451-477. Recuperado de http://www.revistas.unam.mx/index.ph $\mathrm{p} /$ repi/article/view/65284 
Wickham, H. (2014). Tidy data. Journal of Statistical Software, 59(10), 1-23. https://do i.org/10.18637/jss.v059.i10

\section{Apéndice}

\section{Apéndice A. Distribución de Motivos de Consulta Población Adulta}

\begin{tabular}{lcc}
\multicolumn{1}{c}{ Motivo de consulta - Adultos $-N=811$} & Frecuencia & $\%$ \\
\hline Dificultades emocionales y del estado del ánimo & 246 & 30.3 \\
Pérdidas y situaciones de duelo & 87 & 10.7 \\
Información insuficiente & 79 & 9.7 \\
Dificultades en las relaciones de pareja & 54 & 6.7 \\
Dificultades en las relaciones familiares & 52 & 6.4 \\
Dificultades en las relaciones paterno-filiales & 47 & 5.8 \\
Otros & 44 & 5.4 \\
Dificultades relacionadas con rasgos maladaptativos de personalidad & 34 & 4.2 \\
Remisión por instituciones & 26 & 3.2 \\
Diagnóstico psicopatológico & 25 & 3.1 \\
Dificultades con otras personas & 15 & 1.8 \\
Dificultades con la adaptación a nuevas situaciones & 15 & 1.8 \\
Ideación o conducta suicida & 15 & 1.8 \\
Dificultades de aprendizaje. valoración por CI y bajo rendimiento académico & 10 & 1.2 \\
Malttrato o violencia familiar & 10 & 1.2 \\
Relacionados con terceros & 8 & 1 \\
Dificultades en las funciones cognitivas & 7 & 0.9 \\
Abuso sexual & 6 & 0.7 \\
Salud fisica & 6 & 0.7 \\
Interés en el autoconocimiento/proyecto de vida & 6 & 0.7 \\
Exposición a situaciones traumáticas & 6 & 0.7 \\
Conductas adictivas & 4 & 0.5 \\
Problemas de la conducta alimentaria & 3 & 0.4 \\
Conflicto armado y violencia sociopolítica & 2 & 0.2 \\
Alteración o lesión neurológica & 1 & 0.1 \\
Conductas de autolesión sin intención de muerte & 1 & 0.1 \\
Orientación sexual & 1 & 0.1 \\
Condiciones de discapacidad y situaciones de inclusión & 1 & 0.1 \\
\hline & 811 & 100
\end{tabular}

\section{Apéndice B. Distribución de Motivos de Consulta Población Adolescente}

\begin{tabular}{|c|c|c|}
\hline Motivos de consulta - Adolescentes $-N=238$ & Frecuencia & $\%$ \\
\hline Dificultades emocionales y del estado del ánimo & 43 & 18.1 \\
\hline Dificultades del Comportamiento & 41 & 17.2 \\
\hline Información insuficiente & 30 & 12.6 \\
\hline $\begin{array}{l}\text { Dificultades de aprendizaje. Valoración por CI y } \\
\text { bajo rendimiento académico }\end{array}$ & 26 & 10.9 \\
\hline Otros & 15 & 6.3 \\
\hline Dificultades en las relaciones paterno-filiales & 9 & 3.8 \\
\hline Dificultades en las relaciones familiares & 9 & 3.8 \\
\hline Diagnóstico psicopatológico & 9 & 3.8 \\
\hline Remisión por instituciones & 9 & 3.8 \\
\hline Dificultades con otras personas & 7 & 2.9 \\
\hline Pérdidas y situaciones de duelo & 6 & 2.5 \\
\hline Conductas adictivas & 6 & 2.5 \\
\hline Conductas de autolesión sin intención de muerte & 6 & 2.5 \\
\hline Dificultades con la adaptación a nuevas situaciones & 3 & 1.3 \\
\hline Ideación o conducta suicida & 3 & 1.3 \\
\hline Orientación sexual & 3 & 1.3 \\
\hline Dificultades del desarrollo & 2 & 0.8 \\
\hline Problemas de la conducta alimentaria & 2 & 0.8 \\
\hline Exposición a situaciones traumáticas & 2 & 0.8 \\
\hline Dificultades en las relaciones de pareja & 1 & 0.4 \\
\hline Maltrato o violencia familiar & 1 & 0.4 \\
\hline Abuso sexual & 1 & 0.4 \\
\hline Alteración o lesión neurológica & 1 & 0.4 \\
\hline Conducta sexual & 1 & 0.4 \\
\hline Identidad de género & 1 & 0.4 \\
\hline Interés en el autoconocimiento/proyecto de vida & 1 & 0.4 \\
\hline Total & 238 & 100 \\
\hline
\end{tabular}

\section{Apéndice C. Distribución de Motivos de Consulta Población Infantil.}

\begin{tabular}{|c|c|c|}
\hline Motivos de consulta - Población infantil $-N=418$ & Frecuencia & $\%$ \\
\hline Dificultades del Comportamiento & 132 & 31.6 \\
\hline $\begin{array}{l}\text { Dificultades de aprendizaje, valoración por CI y } \\
\text { bajo rendimiento académico }\end{array}$ & 74 & 17.7 \\
\hline Dificultades emocionales y del estado del ánimo & 43 & 10.3 \\
\hline Dificultades del desarrollo & 41 & 9.8 \\
\hline Dificultades en las relaciones paterno-filiales & 25 & 6 \\
\hline Información insuficiente & 21 & 5 \\
\hline Pérdidas y situaciones de duelo & 16 & 3.8 \\
\hline Dificultades en las relaciones familiares & 12 & 2.9 \\
\hline Remisión por instituciones & 7 & 1.7 \\
\hline Diagnóstico psicopatológico & 6 & 1.4 \\
\hline Dificultades con la adaptación a nuevas situaciones & 5 & 1.2 \\
\hline Dificultades con otras personas & 4 & 1 \\
\hline Maltrato o violencia familiar & 4 & 1 \\
\hline Abuso sexual & 4 & 1 \\
\hline Ideación o conducta suicida & 3 & 0.7 \\
\hline Conductas de autolesión sin intención de muerte & 3 & 0.7 \\
\hline Conducta sexual & 3 & 0.7 \\
\hline Otros & 3 & 0.7 \\
\hline Problemas de la conducta alimentaria & 2 & 0.5 \\
\hline Conductas adictivas & 2 & 0.5 \\
\hline Conflicto armado y violencia sociopolítica & 2 & 0.5 \\
\hline $\begin{array}{l}\text { Condiciones de discapacidad y situaciones de } \\
\text { inclusión }\end{array}$ & 2 & 0.5 \\
\hline Exposición a situaciones traumáticas & 2 & 0.5 \\
\hline Dificultades en las funciones cognitivas & 1 & 0.2 \\
\hline Salud física & 1 & 0.2 \\
\hline Total & 418 & 100 \\
\hline
\end{tabular}

\section{Notas}

* Artículo de investigación. 